
\title{
$\begin{array}{ll}\text { Research Square } & \begin{array}{l}\text { Preprints are preliminary reports that have not undergone peer review. } \\ \text { They should not be considered conclusive, used to inform clinical practice, } \\ \text { or referenced by the media as validated information. }\end{array}\end{array}$
}

\section{The interactive effects of pre-pregnancy body mass index, thyroid function, and blood lipid levels on the risk of gestational diabetes mellitus: a crossover analysis}

\author{
Ying Wang \\ Hangzhou Normal University School of Public Health \\ Sha Lu \\ The Affiliated Hangzhou Women's Hospital, Hangzhou Normal University \\ Xianrong $\mathrm{Xu}$ \\ Hangzhou Normal University School of Public Health \\ Lijun Zhang \\ Hangzhou Normal University School of Public Health \\ Jun Yang ( $\nabla$ gastate@zju.edu.cn ) \\ Hangzhou Normal University School of Public Health \\ Wensheng $\mathrm{Hu}$ \\ The Affiliated Hangzhou Women's Hospital, Hangzhou Normal University
}

\section{Research Article}

Keywords: Pre-pregnancy body mass index, Thyroid function, FT3/FT4 ratio, Blood lipid, Interaction, Gestational diabetes mellitus.

Posted Date: January 13th, 2022

DOI: https://doi.org/10.21203/rs.3.rs-1188301/v1

License: (c) (1) This work is licensed under a Creative Commons Attribution 4.0 International License. Read Full License 


\section{Abstract \\ Background}

Studies have demonstrated the associations between pre-pregnancy obesity, thyroid dysfunction, dyslipidemia, and increased risk of gestational diabetes mellitus (GDM) in pregnant women. This study was designed to investigate whether and to what extent, the interactions between these factors contribute to the risk of GDM.

\section{Methods}

A case-control study of 232 GDM cases and 696 controls was conducted among pregnant women from Hangzhou, China. Multiple logistic regression analysis was applied to identify independent risk factors of GDM. Crossover analysis was performed to assess the interactive effects of pre-pregnancy body mass index (pBMI), thyroid hormones, blood lipid profiles on the risk of GDM. The indexes including attributable proportion (AP) to the interaction and the relative excess risk due to interaction (RERI) were calculated.

\section{Results}

Chinese pregnant women with $\mathrm{pBMI}>23 \mathrm{~kg} / \mathrm{m}^{2}$ (adjusted: $\left.\mathrm{OR}=4.162, P<0.001\right)$, high triglyceride levels $(>2.30 \mathrm{mmol} / \mathrm{L})($ adjusted: $\mathrm{OR}=1.735, P<0.001)$ and the free triiodothyronine/free thyroxine (FT3/FT4) ratio $\geq 0.502(\mathrm{OR}=4.162, P<0.001)$ have significantly increased risk of GDM. Crossover analysis indicated that there were significant interactions between pre-pregnancy overweight/obesity and FT3/FT4 $\geq 0.502$ (AP=0.550, $P<0.001 ; \mathrm{RERI}=7.586, P=0.009$ ), high TG levels and $\mathrm{FT} 3 / \mathrm{FT} 4 \geq 0.502(\mathrm{AP}=0.348,95 \% \mathrm{Cl}=0.081 \sim 0.614, P=0.010 ; \mathrm{RERI}=2.021,95 \% \mathrm{Cl}=0.064 \sim 3.978, P=0.043)$ on the risk of $\mathrm{GDM}$.

\section{Conclusion}

The interactions between pBMI and FT3/FT4 ratio, TG level, and FT3/FT4 ratio may have significant impacts on the risk of GDM in pregnant women. Such findings may help improve our understanding of the pathogenesis of GDM as well as develop comprehensive strategies for the management of GDM.

\section{Background}

Gestational diabetes mellitus (GDM) is a common and growing antenatal disease that affects about $9 \%$ 25\% of pregnant women worldwide[1]. It is likely to cause a variety of adverse birth outcomes such as giant babies, fetal growth restriction, fetal distress, premature rupture of membranes, and is accompanied by a high incidence of cesarean delivery, obstructed shoulder delivery, and postpartum hemorrhage [2]. It poses a serious threat to the health of mothers and their offspring and has become a major public health problem[3]. Data from the International Diabetes Federation (IDF) showed that the global incidence of GDM in 2017 was about 14\%, with $9 \%$ in Africa, 12.6\% in North America, and 21\% in Asia[4], respectively. A meta-analysis investigating the prevalence of GDM in East and Southeast Asia showed that the prevalence of GDM in China was 11.91\%, much higher than that of Japan, Korea, and Thailand[5]. Therefore, the prevention and treatment of GDM, as well as identifying causal risk factors, remain a great mission and momentous challenge in China.

Unfortunately, the pathogenesis of GDM is not yet fully understood, and there is evidence that both genetic and environmental factors are important determinants[6]. From the view of prevention, identifying modifiable risk factors for GDM is the first step toward primary prevention. Over the years some risk factors have been identified, such as pre-pregnancy obesity, endocrine factors, advanced age, family history of diabetes, etc[7, 8]. Among them, pre-pregnancy overweight or obesity (body mass index $(\mathrm{BMI}) \geq 25 \mathrm{~kg} / \mathrm{m}^{2}$ ) has been implicated as the most significant risk factor for GDM [9]. It has been shown that prepregnancy $\mathrm{BMI}(\mathrm{pBMI})$ is associated with increased risk of GDM in a dose-response manner[9, 10], and all three obesity phenotypes, namely general, central, and visceral obesity, are consistently associated with an increased risk of GDM in women[11]. Further, there was evidence that pBMI may have interactions with other risk factors for GDM, including environmental[12], genetic[13], or behavioral risk factors[14], but the results were controversial. Interaction studies that assess the combined influence of pBMI and other risk factors may improve our understanding of GDM.

Maternal thyroid dysfunction[15] and dyslipidemia[16] are also important risk factors for GDM. Hypothyroxinemia, as well as subclinical and overt hypothyroidism, were observed to be significantly associated with the risk of GDM[17, 18]. Several cross-sectional studies have shown that the free triiodothyronine (FT3)/free thyroxine (FT4) ratio, a commonly used indicator for thyroid function, is associated with higher insulin resistance, glycated hemoglobin, fasting glucose, post-load glucose levels, and increased risk of GDM in pregnancy women[19, 20 ]. Dyslipidemia was also associated with insulin resistance and $\beta$-cell dysfunction in pregnant women[21] and was found to be an independent predictor for GDM[22]. Moreover, there was evidence that thyroid dysfunction may also be a risk factor for dyslipidemia[23, 24]. Therefore, the comprehensive effects of thyroid dysfunction and dyslipidemia on the risk of GDM need further investigation.

Although previous studies have confirmed that pBMI [25], FT3/FT4 ratio [26], and dyslipidemia [27] are all independent determinants of GDM, their interactive effects on the risk of GDM remain unclear. To address this issue, we performed a case-control study with crossover analysis to investigate the comprehensive effects of pBMI, thyroid hormone, and serum lipids on the risk of GDM in a Chinese population. The results from this study may help to advance our understanding of the pathogenesis of GDM.

\section{Subjects And Methods}


The study was approved by the Ethics Committee of Hangzhou Women's Hospital and was carried out following the approved guidelines.

\section{Participants}

Pregnant women who delivered at Hangzhou Women's Hospital in Zhejiang Province of East China between March 2017 and July 2018 were included. The inclusion criteria were as follows: (1) natural conception, singleton pregnancy; (2) meeting the diagnostic criteria for GDM and no other pregnancy-related diseases; (3) not taking lipid/glycemic/thyroid function-related medications before and during pregnancy; (4) complete basic data and medical history. Exclusion criteria of pregnant women were: (1) multiple pregnancies; (2) diagnosis of type 1 or type 2 diabetes mellitus before or during pregnancy, (3) a history of severe complications including inherited metabolic diseases, cardiovascular disease, thyroid or liver dysfunction; (4) use of drugs that could affect lipid levels, including corticosteroids, etc.; and (5) incomplete pregnancy. We used the same exclusion criteria to identify patients without GDM as the control group, and case and control were matched for age (1:3 ratio). Finally, a total of 232 women with GDM and 696 healthy controls were enrolled in the study.

\section{Anthropometric and biochemical measurements}

Demographic data were collected from the medical records by trained staff including the following basic information: (1) general characteristics (age, height, pre-pregnancy weight, gravidity, history of abortion, etc.); (2) previous or current disease status, family history of diabetes and autoimmune thyroid disease, medication use, and lifestyle habits. BMI was calculated by dividing the weight in kilograms by the height in square meters $\left(\mathrm{kg} / \mathrm{m}^{2}\right)$. We used the WHO expert group's adjusted optimal BMI range for Asian populations for classification, with "non-overweight" defined as BMl<23.00 kg/m² and "overweight/obesity" defined as $B M I \geq 23.00 \mathrm{~kg} / \mathrm{m}^{2}[28]$.

All pregnant women are routinely screened for GDM with a $50 \mathrm{~g}$ glucose challenge test (GCT) between 24 and 28 weeks of gestation. Women with a serum glucose concentration $>140 \mathrm{mg} / \mathrm{dL}(7.8 \mathrm{mmol} / \mathrm{L}) 1 \mathrm{~h}$ after GCT are referred to a diagnostic $100 \mathrm{~g}$ oral glucose tolerance test (OGTT). GDM was diagnosed if at least one of the following criteria were met: (a) fasting plasma glucose $\geq 5.1 \mathrm{mmol} / \mathrm{L}$ ( $92 \mathrm{mg} / \mathrm{dl}$ ); (b) $1 \mathrm{~h} \mathrm{plasma} \mathrm{glucose} \geq 10.0 \mathrm{mmol} / \mathrm{L}$ (180 mg/dl); and (c) $2 \mathrm{~h}$ plasma glucose $\geq 8.5-11.0 \mathrm{mmol} / \mathrm{L}(153-199 \mathrm{mg} / \mathrm{dl})$.

All women underwent a venous blood sample collection at 24-28 gestational weeks. Levels of free triiodothyronine (FT3), free thyroxine (FT4), and thyroidstimulating hormone (TSH) were measured with a Beckman Coulter Unicel DIx 800 Immunoluminescence Analyzer. According to the reference ranges for TSH during pregnancy[29], we categorized all subjects into two groups: normal TSH group (TSH $\leq 3.00 \mathrm{mIU} / \mathrm{L}$ ) and high TSH group (TSH>3.00 mIU/L). Results from Restricted cubic spline plots indicated that the truncated values of FT3/FT4 ratio of the participants were 0.502 participants, thus we also categorized all subjects into two groups: normal FT3/FT4 ( $\geq 0.502)$ and low FT3/FT4 $(<0.502)$.

The triglyceride (TG), total cholesterol (TC), high-density lipoprotein cholesterol (HDL-C), and low-density lipoprotein cholesterol (LDL-C) levels were analyzed by a Beckman Coulter AU5800 automatic biochemistry analyzer. Since there are no diagnostic criteria for hyperlipidemia during pregnancy in China, we defined dyslipidemia in pregnant women under the Guidelines for the Prevention and Treatment of Dyslipidemia in Chinese Adults (Revised 2016)[30]: TG > $200 \mathrm{mg} / \mathrm{dL}(2.30 \mathrm{mmol} / \mathrm{L}), \mathrm{LDL}-\mathrm{C}>160 \mathrm{mg} / \mathrm{dL}(4.10 \mathrm{mmol} / \mathrm{L})$ or $\mathrm{HDL}-\mathrm{C}<40 \mathrm{mg} / \mathrm{dL}(1.30 \mathrm{mmol} / \mathrm{L})$.

\section{Statistical analysis}

All statistical analyses were performed using IBM SPSS Statistics for Windows version 20.0. Continuous data were expressed as mean \pm standard deviation, while categorical data as number $(n, \%)$. Characteristics such as age, gravidity, BMI, FPG, and blood lipid profile at the first prenatal visit were compared between GDM and non-GDM subjects. The non-parametric and chi-square tests were used to compare the differences between groups. The restricted cubic spline analysis was performed to identify the serum FT3/FT4 threshold corresponding to the risk of GDM. Multiple logistic regression was used to evaluate the associations between possible risk factors (thyroid hormones, blood lipid profiles, and pBMI) and the risk of GDM. The interactions between thyroid hormones, blood lipid profiles, and pBMI on the risk of GDM were evaluated by crossover analysis (as described by Knol et al[31]). Multiple comparisons were corrected using the Benjamini-Hochberg method. Statistical significance was defined as $p<0.05$.

\section{Results}

\section{General characteristics of the participants}

Table 1 showed the selected participant characteristics among women with or without GDM. A total of 232 GDM patients and 696 healthy controls were enrolled for final analysis in this study. The average age of the participants was $29.9 \pm 4.0$ years. The proportion of primiparas and multiparas among the participants was $40.8 \%$ and $22.8 \%$, respectively. The average pBMI of the participants was $(22.27 \pm 3.06) \mathrm{kg} / \mathrm{m}^{2}$ in the GDM group, which was significantly higher than that of the control group $\left[(20.55 \pm 1.95) \mathrm{kg} / \mathrm{m}^{2}\right](P<0.001)$. The proportion of overweight/obesity among GDM patients was significantly greater than that of the subjects in the control group $(43.1 \%$ vs.13.6\%, $P<0.001)$. The average FT4 levels were significantly lower among GDM cases, whereas average FT3 levels and the FT3/FT4 ratio were significantly higher among GDM cases than those of controls $(P<0.001)$. TSH levels did not differ significantly between cases and controls. Compared with controls, GDM cases were more likely to have a lower level of TC, LDL-C, and HDL-C ( $P<0.05)$, and a higher level of TG $(P<0.001)$. The proportion of high TG values was significantly higher in GDM cases than that of controls $(P<0.001)$. In contrast, the proportion of high TC, LDL$C$, and HDL-C values showed no significant difference between the cases and controls $(P>0.05)$. 
Table 1

Characteristics of participants with and without gestational diabetes mellitus

\begin{tabular}{|c|c|c|c|c|c|}
\hline \multirow[t]{2}{*}{ Characteristics } & \multirow{2}{*}{$\begin{array}{l}\text { Total } \\
(n=928)\end{array}$} & \multirow{2}{*}{$\begin{array}{l}\text { GDM } \\
(n=232)\end{array}$} & \multirow{2}{*}{$\begin{array}{l}\text { Control } \\
(n=696)\end{array}$} & \multirow[t]{2}{*}{$t / x^{2}$} & \multirow[t]{2}{*}{$P$} \\
\hline & & & & & \\
\hline Age, Mean $\pm S D$, year & $29.9 \pm 4.0$ & $30.3 \pm 4.1$ & $29.8 \pm 3.9$ & -1.905 & 0.057 \\
\hline \multicolumn{6}{|l|}{ History of abortion, n (\%) } \\
\hline No & $537(57.9)$ & $125(53.9)$ & $412(59.2)$ & \multirow[t]{2}{*}{2.017} & \multirow[t]{2}{*}{0.156} \\
\hline Yes & $391(42.1)$ & $107(46.1)$ & $284(40.8)$ & & \\
\hline Gravidity, Mean $\pm S D$ & $2.05 \pm 1.16$ & $2.12 \pm 1.21$ & $2.03 \pm 1.15$ & -0.993 & 0.321 \\
\hline 1 & $379(40.8)$ & $89(38.4)$ & $290(41.7)$ & \multirow[t]{2}{*}{0.786} & \multirow[t]{2}{*}{0.375} \\
\hline$\geq 2$ & $549(59.2)$ & $143(61.6)$ & $406(58.3)$ & & \\
\hline Pre-pregnancy BMI, Mean $\pm S D, k g / m^{2}$ & $20.98 \pm 2.39$ & $22.27 \pm 3.06$ & $20.55 \pm 1.95$ & -8.018 & $<0.001$ \\
\hline$<23.00$ & $733(79.0)$ & $132(56.9)$ & $601(86.4)$ & \multirow[t]{2}{*}{90.949} & \multirow[t]{2}{*}{$<0.001$} \\
\hline$\geq 23.00$ & 195(21.0) & $100(43.1)$ & $95(13.6)$ & & \\
\hline TG,Mean $\pm S D, m m o l / L$ & $2.29 \pm 0.88$ & $2.56 \pm 0.96$ & $2.21 \pm 0.83$ & -4.989 & $<0.001$ \\
\hline$<2.30$ & $565(60.9)$ & $117(50.4)$ & $448(64.4)$ & \multirow[t]{2}{*}{14.191} & \multirow[t]{2}{*}{$<0.001$} \\
\hline$\geq 2.30$ & $363(39.1)$ & $115(49.6)$ & $248(35.6)$ & & \\
\hline $\mathrm{TC}$, Mean $\pm S \mathrm{~S}, \mathrm{mmol} / \mathrm{L}$ & $6.20 \pm 1.06$ & $6.03 \pm 1.08$ & $6.25 \pm 1.05$ & 2.769 & 0.006 \\
\hline$<6.20$ & $482(51.9)$ & $131(56.5)$ & $351(50.4)$ & \multirow[t]{2}{*}{2.538} & \multirow[t]{2}{*}{0.111} \\
\hline$\geq 6.20$ & $446(48.1)$ & $101(43.5)$ & $345(49.6)$ & & \\
\hline LDL-C, Mean $\pm S D, m m o l / L$ & $3.46 \pm 0.82$ & $3.31 \pm 0.82$ & $3.51 \pm 0.81$ & 3.307 & 0.001 \\
\hline$<4.10$ & 737(79.4) & $191(82.3)$ & $546(78.4)$ & \multirow[t]{2}{*}{1.602} & \multirow[t]{2}{*}{0.206} \\
\hline$\geq 4.10$ & 191(20.6) & $41(17.7)$ & $150(21.6)$ & & \\
\hline HDL-C, Mean $\pm S D, m m o l / L$ & $2.30 \pm 0.46$ & $2.15 \pm 0.45$ & $2.36 \pm 0.45$ & 6.268 & $<0.001$ \\
\hline TSH, Mean $\pm S D$, mIU/L & $1.95 \pm 0.79$ & $1.95 \pm 0.74$ & $1.96 \pm 0.81$ & 0.162 & 0.871 \\
\hline$<3.00$ & $838(90.3)$ & 211(90.9) & $627(90.1)$ & \multirow[t]{2}{*}{0.148} & \multirow[t]{2}{*}{0.701} \\
\hline$\geq 3.00$ & $90(9.7)$ & $21(9.1)$ & $69(9.9)$ & & \\
\hline FT3, Mean $\pm S D, p m o l / L$ & $4.28 \pm 0.54$ & $4.51 \pm 0.84$ & $4.20 \pm 0.52$ & -7.697 & $<0.001$ \\
\hline FT4, Mean $\pm S D$,pmol/L & $8.41 \pm 1.19$ & $7.89 \pm 1.12$ & $8.58 \pm 1.16$ & 7.927 & $<0.001$ \\
\hline FT3/FT4, Mean \pm SD & $0.52 \pm 0.10$ & $0.58 \pm 0.11$ & $0.50 \pm 0.09$ & -10.540 & $<0.001$ \\
\hline
\end{tabular}

\section{The association between FT3/FT4 ratio and the risk of GDM}

To investigate the relationship between the FT3/FT4 ratio and the odds ratio (OR) of GDM, a spline curve analysis was performed (Figure 1). The OR of GDM increased with the increment of FT3/FT4 ratio. The FT3/FT4 ratio $\geq 0.502$ was confirmed to be the optimal cut-off value when the OR of FT3/FT4 ratio for GDM risk is equal to 1 (indicating no association). In other words, FT3/FT4 $\geq 0.502$ is a risk factor for the development of GDM, while FT3/FT4<0.502, is "protective" against GDM.

The relationships between FT3/FT4, blood lipid profiles, and pBMI with GDM were assessed by univariate and multiple binary logistic regression, with or without adjustment for age, history of abortion, and gravidity. The FT3/FT4 ratio, pBMI, and TG levels were found to be significantly associated with the risk of GDM (Table 2). Compared with those with FT3/FT4 ratio <0.502, pregnant women with FT3/FT4 ratio $\geq 0.502$ had an increased risk of GDM (unadjusted $\mathrm{OR}=4.248,95 \% \mathrm{Cl}=3.040 \sim 5.936, P<0.001$; adjusted $\mathrm{OR}=4.162,95 \% \mathrm{Cl}=2.974 \sim 5.852, P<0.001)$. Pre-pregnancy overweight/obesity people are more likely to have GDM compared to non-overweight people (unadjusted $\mathrm{OR}=4.793,95 \% \mathrm{Cl}=3.418 \sim 6.721, P<0.001 ;$ adjusted $\mathrm{OR}=4.685,95 \% \mathrm{Cl}=3.329 \sim 6.594, P<0.001$ ). The risk of GDM in women with high TG level $(>2.30 \mathrm{mmol} / \mathrm{L})$ during pregnancy was as 1.776 times as that in women with low TG level $(\leq 2.30 \mathrm{mmol} / \mathrm{L})$ (unadjusted: $\mathrm{OR}=1.776,95 \% \mathrm{Cl}=1.315 \sim 2.398, \mathrm{P}<0.001$; adjusted: $\mathrm{OR}=1.735,95 \% \mathrm{Cl}=1.282 \sim 2.348, P<0.001$ ). 
Table 2

Associations of thyroid function, blood lipid levels and pre-pregnancy BMI with risk of GDM

\begin{tabular}{|c|c|c|c|c|c|}
\hline & & Unadjusted OR (95\% Cl) & Unadjusted $P$ & Adjusted OR (95\% Cl) & Adjusted $P$ \\
\hline TSH & $\geq 3.00 /<3.00$ & $0.904(0.542 \sim 1.510)$ & 0.701 & $0.902(0.540 \sim 1.509)$ & 0.696 \\
\hline FT3/FT4 & $\geq 0.502 /<0.502$ & $4.248(3.040 \sim 5.936)$ & $<0.001$ & $4.162(2.974 \sim 5.825)$ & $<0.001$ \\
\hline pre-pregnancy BMI & $\geq 23.00 \mathrm{~kg} / \mathrm{m}^{2} /<23.00 \mathrm{~kg} / \mathrm{m}^{2}$ & $4.793(3.418 \sim 6.721)$ & $<0.001$ & $4.685(3.329 \sim 6.594)$ & $<0.001$ \\
\hline TG & $\geq 2.30 \mathrm{mmol} / \mathrm{L} /<2.30 \mathrm{mmol} / \mathrm{L}$ & $1.776(1.315 \sim 2.398)$ & $<0.001$ & $1.735(1.282 \sim 2.348)$ & $<0.001$ \\
\hline TC & $\geq 6.20 \mathrm{mmol} / \mathrm{L} /<6.20 \mathrm{mmol} / \mathrm{L}$ & $0.784(0.582 \sim 1.058)$ & 0.112 & $0.777(0.576 \sim 1.049)$ & 0.100 \\
\hline LDL-C & $\geq 4.10 \mathrm{mmol} / \mathrm{L} /<4.10 \mathrm{mmol} / \mathrm{L}$ & $0.781(0.533 \sim 1.146)$ & 0.206 & $0.756(0.514 \sim 1.112)$ & 0.155 \\
\hline \multicolumn{6}{|c|}{ Adjusted for age, history of abortion and gravidity. } \\
\hline \multicolumn{6}{|c|}{$P$ value $<0.05$ was considered statistically significant. } \\
\hline
\end{tabular}

\section{Interaction between FT3/FT4 ratio and pBMI on the risk of GDM}

We further analyzed the interactions among FT3/FT4, pBMl, and blood lipid levels (TG) on the risk of GDM. The pairwise interaction model among the three was at the $2 \times 2$ level. All analyses were compared with or without the adjustment for age, history of abortion, and gravidity. Table 3 showed the interactive effect of FT3/FT4 and pBMI on the risk of GDM. After adjustment for age, history of abortion, and gravidity, compared with those who had a non-risk ratio of FT3/FT4 (<0.502) and non-overweight, overweight, or obese women with a risk ratio of FT3/FT4 ( $\geq 0.502)$ had a significantly higher risk of GDM (OR=13.799, $95 \% \mathrm{Cl}=8.550 \sim 22.271, P<0.001)$. Within the strata of pBMl, pregnant women with a risk ratio of FT3/FT4 had a higher risk of GDM than those at non-risk ratio (OR=3.689, 95\% Cl:1.895 7.179, $P<0.001$ for overweight/obesity women and OR=3.491, 95\%Cl:2.324 5.244, $P<0.001$ for non-overweight women, respectively). Within the strata of FT3/FT4 ratio, pregnant women with overweight/obesity had a significantly higher risk of GDM than those non-overweight pregnant women $(\mathrm{OR}=4.117,95 \% \mathrm{Cl}: 2.692 \sim 6.295, P<0.001$ for those with a risk ratio of FT3/FT4, and OR=3.729, 95\%Cl:1.934 7.190, $P<0.001$ for those with no-risk FT3/FT4 ratio, respectively). A positive interaction was found between overweight/obesity and risk ratio of FT3/FT4 in the additive models (AP=0.550, $95 \% \mathrm{Cl}=0.322 \sim 0.777, P<0.001 ; \mathrm{RERI}=7.586,95 \% \mathrm{Cl}=1.883 \sim 13.289, P=0.009)$.

Table 3

Interaction between $\mathrm{FT} 3 / \mathrm{FT} 4$ and $\mathrm{pBMI}$ for the risk of GDM*

\begin{tabular}{|c|c|c|c|c|c|c|c|}
\hline \multirow{2}{*}{$\begin{array}{l}\text { Thyroid } \\
\text { function }\end{array}$} & \multicolumn{2}{|c|}{ Non-overweight(pBMl<23.00) } & \multicolumn{2}{|c|}{ overweight/obesity (pBMl $\geq 23.00)$} & \multirow{2}{*}{$\begin{array}{l}\text { OR }(95 \% \mathrm{Cl}) \text { for } \\
\text { overweight /obesity } \\
\text { within strata of } \\
\text { thyroid function }\end{array}$} & \multirow{2}{*}{$\begin{array}{l}\text { AP } \\
(95 \% \mathrm{Cl})\end{array}$} & \multirow{2}{*}{$\begin{array}{l}\text { RERI } \\
(95 \% \mathrm{Cl})\end{array}$} \\
\hline & $\begin{array}{l}\text { GDM/Control } \\
\text { (n) }\end{array}$ & $\mathrm{OR}(95 \% \mathrm{Cl})$ & $\begin{array}{l}\text { GDM/Control } \\
\text { (n) }\end{array}$ & $\mathrm{OR}(95 \% \mathrm{Cl})$ & & & \\
\hline \multicolumn{6}{|l|}{ FT3/FT4 } & \multirow{4}{*}{$\begin{array}{l}0.550 \\
(0.322 \sim 0.777) \\
P<0.001\end{array}$} & \multirow{2}{*}{$\begin{array}{l}7.586 \\
(1.883 \sim 13.289) \\
P=0.009\end{array}$} \\
\hline $\begin{array}{l}\text { Non-risk } \\
\text { ratio }(<0.502)\end{array}$ & $40 / 363$ & 1 & $17 / 41$ & $\begin{array}{l}3.729(1.934 \sim 7.190) \\
P<0.001\end{array}$ & $\begin{array}{l}3.729(1.934 \sim 7.190) \\
P<0.001\end{array}$ & & \\
\hline $\begin{array}{l}\text { Risk ratio } \\
(\geq 0.502)\end{array}$ & $92 / 238$ & $\begin{array}{l}3.491(2.324 \sim 5.244) \\
P<0.001\end{array}$ & $83 / 54$ & $\begin{array}{l}13.79 \\
(8.550 \sim 22.271) \\
P<0.001\end{array}$ & $\begin{array}{l}4.117(2.692 \sim 6.295) \\
P<0.001\end{array}$ & & \\
\hline $\begin{array}{l}\text { OR }(95 \% \mathrm{Cl}) \\
\text { for risk ratio } \\
\text { within strata }\end{array}$ & & $\begin{array}{l}3.491(2.324 \sim 5.244) \\
P<0.001\end{array}$ & & $\begin{array}{l}3.689(1.895 \sim 7.179) \\
P<0.001\end{array}$ & & & \\
\hline
\end{tabular}

of $\mathrm{pBMl}$

*Adjusted for age, history of abortion and gravidity; $P$ value $<0.05$ was considered statistically significant. RERI: relative excess risk due to interaction; AP: attributable proportion to the interaction.

\section{Interaction between FT3/FT4 ratio and blood lipid levels on the risk of GDM}

Table 4 showed the effect of the interaction between FT3/FT4 and blood lipid levels for the risk of GDM. After adjustment for age, history of abortion, and gravidity, compared with those with low TG levels and the non-risk ratio of FT3/FT4, pregnant women with high TG levels and a risk ratio of FT3/FT4 had a significantly higher risk for GDM (OR $=5.812,95 \% \mathrm{Cl}: 3.733 \sim 9.049, P<0.001)$. Within the strata of the risk ratio of FT3/FT4, pregnant women with high TG levels had a significantly higher risk of GDM $(\mathrm{OR}=1.648,95 \% \mathrm{Cl}=1.127 \sim 2.410, P=0.010)$. Within the strata of TG levels, pregnant women with a risk ratio of $\mathrm{FT} / \mathrm{FT} 4$ had a higher risk of GDM than those with a non-risk ratio (OR=4.603, 95\% Cl:2.688 7.881, $P<0.001$ for those with high TG levels, and OR=3.551,

$95 \% \mathrm{Cl}: 2.289 \sim 5.508, P<0.001$ for those with low TG levels). A positive interaction was found between high TG levels and risk ratio of FT3/FT4 in the additive models ( $\mathrm{AP}=0.348,95 \% \mathrm{Cl}=0.081 \sim 0.614, P=0.010 ; \mathrm{RERI}=2.021,95 \% \mathrm{Cl}=0.064 \sim 3.978, P=0.043)$. 
Table 4

Interaction between FT3/FT4 and blood lipid levels for the risk of GDM

\begin{tabular}{|c|c|c|c|c|c|c|c|}
\hline \multirow{2}{*}{$\begin{array}{l}\text { blood } \\
\text { lipid } \\
\text { levels }\end{array}$} & \multicolumn{2}{|c|}{ Non-risk ratio(FT3/FT4<0.502) } & \multicolumn{2}{|c|}{ 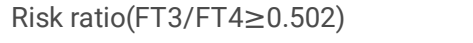 } & \multirow{2}{*}{$\begin{array}{l}\text { OR( } 95 \% \mathrm{Cl}) \text { for risk } \\
\text { ratio within strata } \\
\text { of blood lipid levels }\end{array}$} & \multirow[t]{2}{*}{$\mathrm{AP}(95 \% \mathrm{Cl})$} & \multirow[t]{2}{*}{$\operatorname{RERI}(95 \% \mathrm{Cl})$} \\
\hline & $\begin{array}{l}\text { GDM/Control } \\
\text { (n) }\end{array}$ & $\mathrm{OR}(95 \% \mathrm{Cl})$ & $\begin{array}{l}\text { GDM/Control } \\
\text { (n) }\end{array}$ & $\mathrm{OR}(95 \% \mathrm{Cl})$ & & & \\
\hline \multicolumn{6}{|l|}{ TG } & \multirow{7}{*}{$\begin{array}{l}0.348 \\
(0.081 \sim 0.614)\end{array}$} & $2.021(0.064 \sim 3.978)$ \\
\hline \multirow{2}{*}{$\begin{array}{l}\text { Low } \\
\text { levels } \\
(<2.30)\end{array}$} & \multirow[t]{2}{*}{$36 / 277$} & \multirow[t]{2}{*}{1} & \multirow[t]{2}{*}{$81 / 171$} & $3.551(2.289 \sim 5.508)$ & $3.551(2.289 \sim 5.508)$ & & \multirow[t]{6}{*}{$P=0.043$} \\
\hline & & & & $P<0.001$ & $P<0.001$ & & \\
\hline \multirow{2}{*}{$\begin{array}{l}\text { High } \\
\text { levels } \\
(\geq 2.30)\end{array}$} & \multirow[t]{2}{*}{$21 / 127$} & $1.241(0.694 \sim 2.218)$ & \multirow[t]{2}{*}{$94 / 121$} & $5.812(3.733 \sim 9.049)$ & $4.603(2.688 \sim 7.881)$ & & \\
\hline & & $P=0.466$ & & $P<0.001$ & $P<0.001$ & & \\
\hline \multirow{2}{*}{$\begin{array}{l}\text { OR (95\% } \\
\text { Cl) for } \\
\text { high TG } \\
\text { levels } \\
\text { within } \\
\text { strata of } \\
\text { thyroid } \\
\text { function }\end{array}$} & & \multicolumn{2}{|l|}{$1.241(0.694 \sim 2.218)$} & $1.648(1.127 \sim 2.410)$ & & & \\
\hline & & $P=0.466$ & & $P=0.010$ & & & \\
\hline \multicolumn{8}{|c|}{ Adjusted for age, history of abortion and gravidity. } \\
\hline \multicolumn{8}{|c|}{$P$ value $<0.05$ was considered statistically significant. } \\
\hline
\end{tabular}

\section{Interaction between pBMI and blood lipid levels on the risk of GDM}

Table 5 showed the interactive effects between pBMI and blood lipid levels for the risk of GDM. After adjustment for age, history of abortion, and gravidity, compared with non-overweight people with a non-risk ratio of FT3/FT4, pregnant women with overweight/obesity and risk ratio of FT3/FT4 had a significantly higher risk of $\mathrm{GDM}(\mathrm{OR}=6.751,95 \% \mathrm{Cl}=4.203 \sim 10.843, P<0.001)$. Within the strata of non-overweight, people with high TG levels had a significantly higher risk of GDM $(\mathrm{OR}=1.610,95 \% \mathrm{Cl}=1.097 \sim 2.363, P=0.015)$. Within the strata of TG levels, pregnant women with overweight/obesity had a significantly higher risk of GDM than those non-overweight pregnant women (OR=4.771, 95\% Cl=2.961 7.688, $P<0.001$ for women with low TG levels, and OR=4.164,

$95 \% \mathrm{Cl}=2.540 \sim 6.826, P<0.001$ for women with high TG levels). The interaction between $\mathrm{pBMI}$ and TG levels was not significant in the additive models ( $P$-value for RERI and AP were $>0.05$ ).

Table 5

Interaction between pBMI and blood lipid levels for the risk of GDM

\begin{tabular}{|c|c|c|c|c|c|c|c|}
\hline \multirow{2}{*}{$\begin{array}{l}\text { blood } \\
\text { lipid } \\
\text { levels }\end{array}$} & \multicolumn{2}{|c|}{ Non-overweight(pBMl<23.00) } & \multicolumn{2}{|c|}{ Overweight(pBMl $\geq 23.00$ ) } & \multirow{2}{*}{$\begin{array}{l}\text { OR( }(95 \% \mathrm{Cl}) \text { for risk } \\
\text { ratio within strata } \\
\text { of blood lipid levels }\end{array}$} & \multirow[t]{2}{*}{$\mathrm{AP}(95 \% \mathrm{Cl})$} & \multirow[t]{2}{*}{ RERI $(95 \% \mathrm{Cl})$} \\
\hline & $\begin{array}{l}\text { GDM/Control } \\
\text { (n) }\end{array}$ & $\mathrm{OR}(95 \% \mathrm{Cl})$ & $\begin{array}{l}\text { GDM/Control } \\
\text { (n) }\end{array}$ & $\mathrm{OR}(95 \% \mathrm{Cl})$ & & & \\
\hline TG & & & & & & 0.203 & 1.370 \\
\hline \multirow{2}{*}{$\begin{array}{l}\text { Low } \\
\text { levels } \\
(<2.30)\end{array}$} & \multirow[t]{2}{*}{$72 / 397$} & \multirow[t]{2}{*}{1} & \multirow[t]{2}{*}{$60 / 204$} & $4.771(2.961 \sim 7.688)$ & $4.771(2.961 \sim 7.688)$ & $(-0.229 \sim 0.635)$ & \multirow[t]{6}{*}{$(-1.958 \sim 4.698) P=0.4$} \\
\hline & & & & $P<0.001$ & $P<0.001$ & $P=0.357$ & \\
\hline \multirow{2}{*}{$\begin{array}{l}\text { High } \\
\text { levels } \\
(\geq 2.30)\end{array}$} & \multirow[t]{2}{*}{$45 / 51$} & 1.610(1.097 2.363) & \multirow[t]{2}{*}{$55 / 44$} & $6.751(4.203 \sim 10.843)$ & $4.164(2.540 \sim 6.826)$ & & \\
\hline & & $P=0.015$ & & $P<0.001$ & $P<0.001$ & & \\
\hline \multirow[b]{2}{*}{$\begin{array}{l}\text { OR } \\
(95 \% \\
\text { Cl) for } \\
\text { high } \\
\text { TG } \\
\text { levels } \\
\text { within } \\
\text { strata } \\
\text { of } \\
\text { pBMI }\end{array}$} & & 1.610(1.097 2.363) & & $1.437(0.815 \sim 2.532)$ & & & \\
\hline & & $P=0.015$ & & $P=0.210$ & & & \\
\hline
\end{tabular}

Adjusted for age, history of abortion and gravidity.

$P$ value $<0.05$ was considered statistically significant.

RERI: relative excess risk due to interaction; AP: attributable proportion to the interaction. 


\section{Discussion}

GDM is a complex disease that is promoted by interactions between multiple genetic and environmental factors[3]. Several studies had found the interactions between ethnicity, age, and pBMI[32, 33], genetic and nutritional factors on the risk of GDM[34]. Other studies had confirmed the interactive effects of modified risk factors, including diet, physical activity, and psychological well-being on the risk of GDM [35]. Thus, clarification of these interactions may lead to a better understanding of the mechanism underlying GDM as well as specifically designed policies and programs for prevention.

In line with previous studies[36, 37], in this case-control study, we found overweight and obesity before pregnancy, high serum TG levels, and FT3/FT4 ratio were correlated with increased risk of GDM. Moreover, we observed a significant interactive effect between pBMI and FT3/FT4 ratio on the risk of GDM. In additive models incorporating pBMI and FT3/FT4 ratio, there was a statistically significant positive interaction between pre-pregnancy overweight/obesity and FT3/FT4 risk ratio ( $\mathrm{AP}=0.550,95 \% \mathrm{Cl}=0.322 \sim 0.777, P<0.001 ; \mathrm{RERI}=7.586,95 \% \mathrm{Cl}=1.883 \sim 13.289, P=0.009)$. These results indicated that thyroid hormone levels modified the effect of pre-pregnancy obesity on the risk of GDM, and the risk of GDM attributable to the interaction is as high as $55.0 \%$. To our best knowledge, this study is one of the first to examine the interaction between pBMI and thyroid function on the risk of GDM. Obesity is the most important risk factor for GDM, contributing to $46.3 \%$ of the overall population-attributable fraction risk in pregnant women[38]. FT3/FT4 ratio, a commonly used proxy for peripheral deiodinase activity [39], is elevated and associated with poorer metabolic parameters such as unfavorable lipids profiles, blood pressure, and insulin resistance[40,41]. Though the underlying mechanisms of the interaction have not been fully elucidated, the increment of FT3/FT4 ratio was demonstrated to be associated with higher fasting glucose, glycated hemoglobin concentrations, and insulin resistance[42, 43]. Moreover, elevated FT3/FT4 ratio may reflect the presence of metabolic syndrome components and high levels of adipose-related inflammatory markers in the participants[44]. Therefore, pregnant women with both overweight/obesity and elevated FT3/FT4 ratio were prone to have a higher risk of GDM. Future experimental and randomized controlled studies are needed to confirm our findings and to better understand the biological mechanisms underlying this interaction.

In addition, a significant interaction between high TG levels and FT3/FT4 ratio $(\geq 0.502)$ on the risk of GDM in pregnant women was also identified in our study ( $\mathrm{AP}=0.348,95 \% \mathrm{Cl}=0.081 \sim 0.614, P=0.010 ; \mathrm{RERI}=2.021,95 \% \mathrm{Cl}=0.064 \sim 3.978, P=0.043)$. The result indicated that $34.8 \%$ of the $\mathrm{GDM}$ risk could be attributed to the presence of interaction between thyroid hormone and TG levels in pregnant women. Dyslipidemia during pregnancy, especially hypertriglyceridemia, was closely associated with a greater risk of GDM[21, 45], and the possible mechanisms including impaired insulin action, $\beta$-cell function, and nitric oxide signaling[21, 46]. As shown by a previous study, FT3/FT4 ratio was positively associated with multiple risk factors for GDM, including homeostasis model assessment of insulin resistance (HOMA-IR), waist circumference, triglyceride levels, fasting blood glucose, and systolic blood pressure[47]. Therefore, the co-presence of high TG and FT3/FT4 ratio may synergistically increase the risk of GDM. Further, there was study indicated that $67.9 \%$ of the association between higher FT3/FT4 ratio and increased risk of GDM might be mediated through the composite effect of some lipids [19]. As it is well known that thyroid hormones can affect serum lipid levels[48], we speculated that the interactive effect of higher TG level and FT3/FT4 ratio on the risk of GDM may be, at least partly, mediated through the regulation of serum lipids.

There are several advantages to our study. First, we explored the effects of pBMI, thyroid hormones, and serum lipids during pregnancy and their interactions on the risk of GDM. To our knowledge, it is the first study to explore these interactions by using crossover methodology. Second, we chose FT3/FT4 ratio as an indicator of thyroid hormone status, which has been demonstrated to be a stable and better predictor of insulin resistance and metabolic syndrome[49]. Third, we used the interaction presentation table recommended by Knol et al.[50] to report OR value, AP values, RERI interaction indices, and $95 \% \mathrm{Cl}$. This analysis could provide not only the respective main effects of different risk factors but also the interactive values of the two factors on diseases based on different models. Fourth, the basic data of pregnant women including age, pre-pregnancy weight, pregnancy, and maternal delivery, as well as various clinical biochemical data such as serum thyroid hormone and lipid levels were all obtained from the hospital medical record files, thus reducing the errors caused by self-reporting.

Some limitations should also be noticed in our study. First, although some potential confounding factors were controlled statistically, we cannot rule out the residual confounding effects that may affect some of our findings. Thus, interpreting the results of the present study should be done with caution. Second, due to the nature of the case-control study, the specific mechanisms and the causal associations could not be explored. Therefore, a larger sample size, welldesigned cohort studies are warranted for further exploration and verification. In addition, as it is a single-center study in China, the findings from this study cannot be generalized nationally or to other ethnic populations.

\section{Conclusion}

Taken together, our study demonstrated that pBMI, thyroid function during pregnancy (FT3/FT4), and lipid levels (TG) were all associated with increased risk of GDM. The interactions between pBMI and FT3/FT4 ratio, TG level, and FT3/FT4 ratio may have significant impacts on the risk of GDM in pregnant women. The findings from our study may help to improve our understanding of the pathogenesis of GDM as well as develop comprehensive strategies for the management of the disease.

\section{Abbreviations}

GDM, gestational diabetes mellitus; pBMI, pre-pregnancy body mass index; FT3, free triiodothyronine $\triangle \mathrm{FT} 4$, free thyroxine; TSH, thyroid-stimulating hormone; TG, triglyceride (TG); TC, total cholesterol; HDL-C, high-density lipoprotein cholesterol; LDL-C, low-density lipoprotein cholesterol; AP, attributable proportion to the interaction; RERI, the relative excess risk due to interaction. 


\section{Declarations}

\section{Acknowledgments}

The authors would like to thank all the participants for their contribution to the study.

\section{Author's contribution}

Y.W. collected and analyzed the data, wrote the first draft of the manuscript. S.L. contributed to study design, collected data and assisted with data analysis, critically reviewed and revised the manuscript. X.X. contributed to study design, collected data, and critically reviewed and revised the manuscript. L.Z. contributed to study design, collected data, and critically reviewed and revised the manuscript. J.Y. conceptualized and designed the study, contributed to analyses and critically reviewed and revised the manuscript. W.H. conceptualized and designed the study, contributed to analyses and critically reviewed and revised the manuscript.

\section{Ethics approval and consent to participate}

All procedures were approved by the Ethics Committee of Hangzhou Women's Hospital (approval No.:201800901) and was carried out following the approved guidelines. Written informed consent was obtained from all subjects who agreed to participate.

\section{Consent for publication}

No applicable.

\section{Availability of data and materials}

No applicable.

\section{Competing interests}

The authors declare that they have no competing interests.

\section{Funding}

This work was supported in part by grants from the National Natural Science Foundation of China (Nos. 31971138 and 81602795 ), the Natural Science Foundation of Zhejiang Province (Nos. LQ15H260002, LZ19H260001, and LY19H260002), the Major Science and Technology Projects of Medicine and Health in Zhejiang Province (WKJ-ZJ-1911) and the Key Project of Hangzhou Health Science and Technology Plan (ZD20200035).

\section{Availability of Data and Materials}

The data that support the findings of this study are available from The Affiliated Hangzhou Women's Hospital of Hangzhou Normal University but restrictions apply to the availability of these data, which were used under license for the current study, and so are not publicly available. Data are however available from the authors upon reasonable request and with permission of The Affiliated Hangzhou Women's Hospital of Hangzhou Normal University.

\section{References}

1. American Diabetes Association: Diagnosis and classification of diabetes mellitus. Diabetes Care 2013, 36 Suppl 1(Suppl 1):S67-74.

2. Expert Committee on the Diagnosis and Classification of Diabetes Mellitus: Report of the Expert Committee on the Diagnosis and Classification of Diabetes Mellitus. Diabetes Care 2000, 23 Suppl 1:S4-19.

3. McIntyre HD, Catalano P, Zhang C, Desoye G, Mathiesen ER, Damm P: Gestational diabetes mellitus. Nat Rev Dis Primers 2019, 5(1):47.

4. Abenhaim HA, Kinch RA, Morin L, Benjamin A, Usher R: Effect of prepregnancy body mass index categories on obstetrical and neonatal outcomes. Arch Gynecol Obstet 2007, 275(1):39-43.

5. Nguyen CL, Pham NM, Binns CW, Duong DV, Lee AH: Prevalence of Gestational Diabetes Mellitus in Eastern and Southeastern Asia: A Systematic Review and Meta-Analysis. J Diabetes Res 2018, 2018:6536974.

6. Zhang C, Rawal S, Chong YS: Risk factors for gestational diabetes: is prevention possible? Diabetologia 2016, 59(7):1385-1390.

7. Moon JH, Kwak SH, Jang HC: Prevention of type 2 diabetes mellitus in women with previous gestational diabetes mellitus. Korean J Intern Med 2017, 32(1):26-41.

8. Leng J, Shao P, Zhang C, Tian H, Zhang F, Zhang S, Dong L, Li L, Yu Z, Chan JC et al: Prevalence of gestational diabetes mellitus and its risk factors in Chinese pregnant women: a prospective population-based study in Tianjin, China. PLoS One 2015, 10(3):e0121029.

9. Najafi F, Hasani J, Izadi N, Hashemi-Nazari SS, Namvar Z, Mohammadi S, Sadeghi M: The effect of prepregnancy body mass index on the risk of gestational diabetes mellitus: A systematic review and dose-response meta-analysis. Obes Rev 2019, 20(3):472-486.

10. Najafi F, Hasani J, Izadi N, Hashemi-Nazari SS, Namvar Z, Shamsi H, Erfanpoor S: Risk of gestational diabetes mellitus by pre-pregnancy body mass index: A systematic review and meta-analysis. Diabetes Metab Syndr 2021, 15(4):102181.

11. Alwash SM, Mclntyre HD, Mamun A: The association of general obesity, central obesity and visceral body fat with the risk of gestational diabetes mellitus: Evidence from a systematic review and meta-analysis. Obes Res Clin Pract 2021. 
12. Marie C, Leger S, Guttmann A, Riviere O, Marchiset N, Lemery D, Vendittelli F, Sauvant-Rochat MP: Exposure to arsenic in tap water and gestational diabetes: A French semi-ecological study. Environ Res 2018, 161:248-255.

13. Feng Y, Jiang CD, Chang AM, Shi Y, Gao J, Zhu L, Zhang Z: Interactions among insulin resistance, inflammation factors, obesity-related gene polymorphisms, environmental risk factors, and diet in the development of gestational diabetes mellitus. J Matern Fetal Neonatal Med 2019, 32(2):339347.

14. Leng J, Wang P, Shao P, Zhang C, Li W, Li N, Wang L, Nan H, Yu Z, Hu G et al: Passive smoking increased risk of gestational diabetes mellitus independently and synergistically with prepregnancy obesity in Tianjin, China. Diabetes Metab Res Rev 2017, 33(3).

15. Huang K, Xu Y, Yan S, Li T, Xu Y, Zhu P, Tao F: Isolated effect of maternal thyroid-stimulating hormone, free thyroxine and antithyroid peroxidase antibodies in early pregnancy on gestational diabetes mellitus: a birth cohort study in China. Endocr J 2019, 66(3):223-231.

16. O'Malley EG, Reynolds CME, Killalea A, O'Kelly R, Sheehan SR, Turner MJ: Maternal obesity and dyslipidemia associated with gestational diabetes mellitus (GDM). Eur J Obstet Gynecol Reprod Biol 2020, 246:67-71.

17. Luo J, Wang X, Yuan L, Guo L: Association of thyroid disorders with gestational diabetes mellitus: a meta-analysis. Endocrine 2021, 73(3):550-560.

18. Li X, Zuo J, Li YH, Tang YP, Bao YR, Ying H: Association between thyroid function and risk of gestational diabetes mellitus in assisted pregnancies: A retrospective cohort study. Diabetes Res Clin Pract 2021, 171:108590.

19. Wang Y, Sun F, Wu P, Huang Y, Ye Y, Yang X, Yuan J, Liu Y, Zeng H, Wen Y et al: A prospective study of early-pregnancy thyroid markers, lipid species, and risk of gestational diabetes mellitus. J Clin Endocrinol Metab 2021.

20. Rawal S, Tsai MY, Hinkle SN, Zhu Y, Bao W, Lin Y, Panuganti P, Albert PS, Ma RCW, Zhang C: A Longitudinal Study of Thyroid Markers Across Pregnancy and the Risk of Gestational Diabetes. J Clin Endocrinol Metab 2018, 103(7):2447-2456.

21. Eppel D, Feichtinger M, Lindner T, Kotzaeridi G, Rosicky I, Yerlikaya-Schatten G, Eppel W, Husslein P, Tura A, Gobl CS: Association between maternal triglycerides and disturbed glucose metabolism in pregnancy. Acta Diabeto/ 2021, 58(4):459-465.

22. Han ES, Krauss RM, Xu F, Sridhar SB, Ferrara A, Quesenberry CP, Hedderson MM: Prepregnancy Adverse Lipid Profile and Subsequent Risk of Gestational Diabetes. J Clin Endocrinol Metab 2016, 101(7):2721-2727.

23. Wang JJ, Zhuang ZH, Shao CL, Yu CQ, Wang WY, Zhang K, Meng XB, Gao J, Tian J, Zheng JL et al: Assessment of causal association between thyroid function and lipid metabolism: a Mendelian randomization study. Chin Med J (Engl) 2021, 134(9):1064-1069.

24. Gu Y, Meng G, Zhang Q, Liu L, Wu H, Zhang S, Wang Y, Zhang T, Wang X, Cao X et al: Thyroid function and lipid profile in euthyroid adults: the TCLSIH cohort study. Endocrine 2020, 70(1):107-114

25. Yong HY, Mohd Shariff Z, Mohd Yusof BN, Rejali Z, Tee YYS, Bindels J, van der Beek EM: Independent and combined effects of age, body mass index and gestational weight gain on the risk of gestational diabetes mellitus. Sci Rep 2020, 10(1):8486.

26. S, Tsai MY, Hinkle SN, Zhu Y, Bao W, Lin Y, Panuganti P, Albert PS, Ma RCW, Zhang C: A Longitudinal Study of Thyroid Markers Across Pregnancy and the Risk of Gestational Diabetes. J Clin Endocrinol Metab 2018, 103(7):2447-2456.

27. Pazhohan A, Rezaee Moradali M, Pazhohan N: Association of first-trimester maternal lipid profiles and triglyceride-glucose index with the risk of gestational diabetes mellitus and large for gestational age newborn. J Matern Fetal Neonatal Med 2019, 32(7):1167-1175.

28. Choo V: WHO reassesses appropriate body-mass index for Asian populations. Lancet 2002, 360(9328):235.

29. Alexander EK, Pearce EN, Brent GA, Brown RS, Chen H, Dosiou C, Grobman WA, Laurberg P, Lazarus JH, Mandel SJ et al: 2017 Guidelines of the American Thyroid Association for the Diagnosis and Management of Thyroid Disease During Pregnancy and the Postpartum. Thyroid 2017, 27(3):315-389.

30. Joint committee for guideline revision: 2016 Chinese guidelines for the management of dyslipidemia in adults. J Geriatr Cardio/ 2018, 15(1):1-29.

31. Knol M, VanderWeele TJljoe: Recommendations for presenting analyses of effect modification and interaction. 2012, 41(2):514-520.

32. Read SH, Rosella LC, Berger H, Feig DS, Fleming K, Ray JG, Shah BR, Lipscombe LL: BMI and risk of gestational diabetes among women of South Asian and Chinese ethnicity: a population-based study. Diabetologia 2021, 64(4):805-813.

33. Li G, Wei T, Ni W, Zhang A, Zhang J, Xing Y, Xing Q: Incidence and Risk Factors of Gestational Diabetes Mellitus: A Prospective Cohort Study in Qingdao, China. Front Endocrinol (Lausanne) 2020, 11:636.

34. Wang H, Yang W, Liu J, Leng J, Li W, Yu Z, Li J, Ma RCW, Hu G, Fang Z et al: Serum concentrations of SFAs and CDKAL1 single-nucleotide polymorphism rs7747752 are related to an increased risk of gestational diabetes mellitus. Am J Clin Nutr 2021.

35. Gilbert L, Gross J, Lanzi S, Quansah DY, Puder J, Horsch A: How diet, physical activity and psychosocial well-being interact in women with gestational diabetes mellitus: an integrative review. BMC Pregnancy Childbirth 2019, 19(1):60.

36. Zhu B, Han Y, Deng F, Huang K, Yan S, Hao J, Zhu P, Tao F: The role of triiodothyronine (T3) and T3/free thyroxine (fT4) in glucose metabolism during pregnancy: the Ma'anshan birth cohort study. Endocr Connect 2021, 10(7):685-693.

37. Hu M, Gu X, Niu Y, Lu W, Huang C, Tang Q, Wu J: Elevated serum triglyceride levels at first prenatal visit is associated with the development of gestational diabetes mellitus. Diabetes Metab Res Rev 2021:e3491.

38. Kim SY, England L, Wilson HG, Bish C, Satten GA, Dietz P: Percentage of gestational diabetes mellitus attributable to overweight and obesity. Am J Public Health 2010, 100(6):1047-1052.

39. Mullur R, Liu YY, Brent GA: Thyroid hormone regulation of metabolism. Physiol Rev 2014, 94(2):355-382.

40. Mehran L, Amouzegar A, Tohidi M, Moayedi M, Azizi F: Serum free thyroxine concentration is associated with metabolic syndrome in euthyroid subjects. Thyroid 2014, 24(11):1566-1574.

Page 9/11 
41. Garduño-Garcia Jde J, Alvirde-Garcia U, López-Carrasco G, Padilla Mendoza ME, Mehta R, Arellano-Campos O, Choza R, Sauque L, Garay-Sevilla ME, Malacara JM et al: TSH and free thyroxine concentrations are associated with differing metabolic markers in euthyroid subjects. Eur $\mathrm{J}$ Endocrino/ 2010 , 163(2):273-278.

42. Knight BA, Shields BM, Hattersley AT, Vaidya B: Maternal hypothyroxinaemia in pregnancy is associated with obesity and adverse maternal metabolic parameters. Eur J Endocrinol 2016, 174(1):51-57.

43. Jing S, Xiaoying D, Ying X, Rui L, Mingyu G, Yuting C, Yanhua Y, Yufan W, Haiyan S, Yongde P: Different levels of thyroid hormones between impaired fasting glucose and impaired glucose tolerance: free T3 affects the prevalence of impaired fasting glucose and impaired glucose tolerance in opposite ways. Clin Endocrinol (Oxf) 2014, 80(6):890-898.

44. Urrunaga-Pastor D, Guarnizo-Poma M, Moncada-Mapelli E, Aguirre LG, Lazaro-Alcantara H, Paico-Palacios S, Pantoja-Torres B, Benites-Zapata VA, Insulin R, Metabolic Syndrome Research G: High free triiodothyronine and free-triiodothyronine-to-free-thyroxine ratio levels are associated with metabolic syndrome in a euthyroid population. Diabetes Metab Syndr 2018, 12(2):155-161.

45. Bao W, Dar S, Zhu Y, Wu J, Rawal S, Li S, Weir NL, Tsai MY, Zhang C: Plasma concentrations of lipids during pregnancy and the risk of gestational diabetes mellitus: A longitudinal study. J Diabetes 2018, 10(6):487-495.

46. Contreras-Duarte S, Claudette $\mathrm{C}$, Farias $\mathrm{M}$, Leiva A: High total cholesterol and triglycerides levels increase arginases metabolism, impairing nitric oxide signaling and worsening fetoplacental endothelial dysfunction in gestational diabetes mellitus pregnancies. Biochim Biophys Acta Mol Basis Dis 2021:166216.

47. Park SY, Park SE, Jung SW, Jin HS, Park IB, Ahn SV, Lee S: Free triiodothyronine/free thyroxine ratio rather than thyrotropin is more associated with metabolic parameters in healthy euthyroid adult subjects. Clin Endocrinol (Oxf) 2017, 87(1):87-96.

48. Ritter MJ, Amano I, Hollenberg AN: Thyroid Hormone Signaling and the Liver. Hepatology 2020, 72(2):742-752.

49. Chen X, Zheng X, Ding Z, Su Y, Wang S, Cui B, Xie Z: Relationship of gender and age on thyroid hormone parameters in a large Chinese population. Arch Endocrinol Metab 2020, 64(1):52-58.

50. Knol MJ, VanderWeele TJ: Recommendations for presenting analyses of effect modification and interaction. Int J Epidemio/ 2012, 41(2):514-520.

\section{Figures}

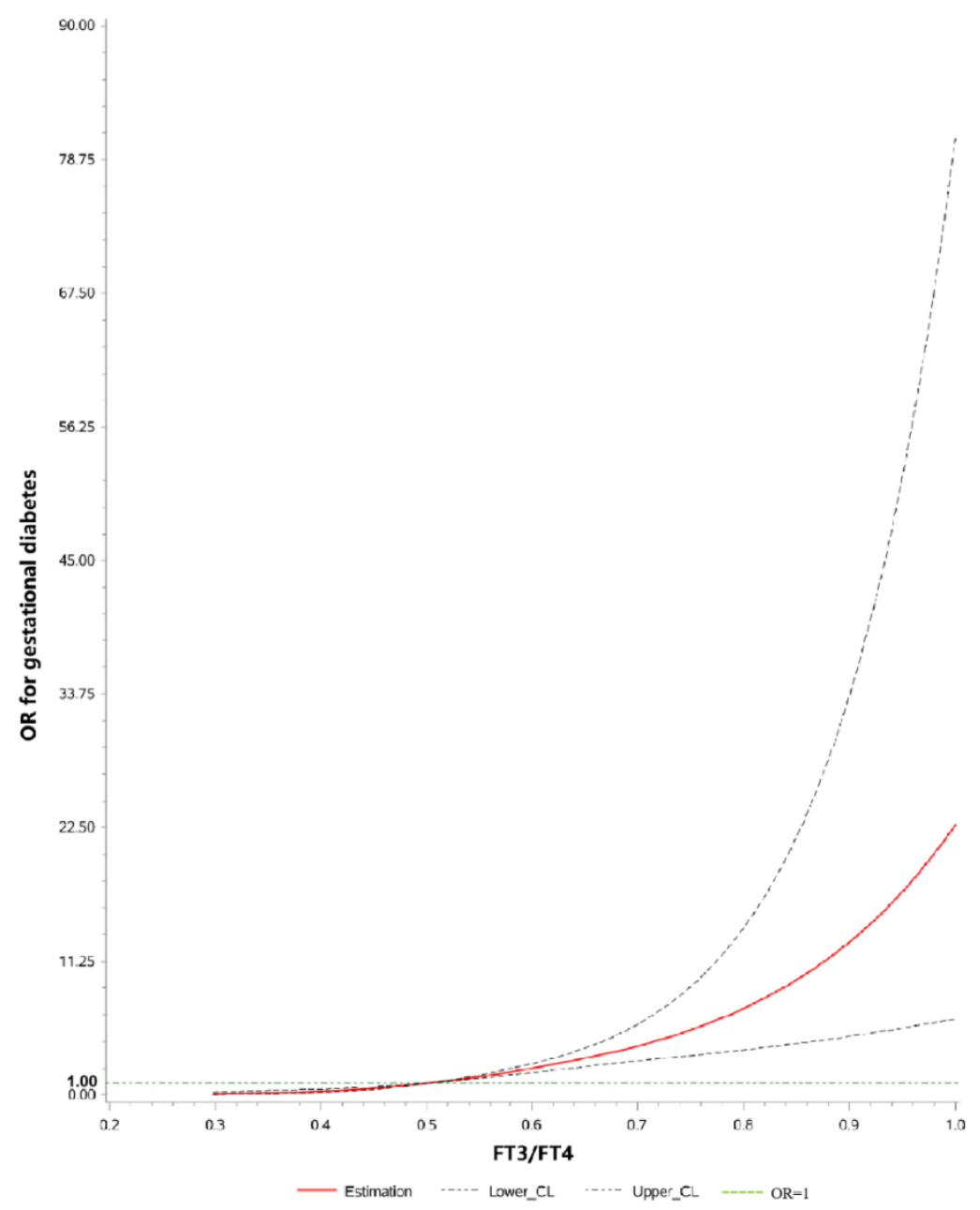

Page $10 / 11$ 
Figure 1

Dose-response relationship between FT3/FT4 ratio and the risk of gestational diabetes mellitus in pregnancy women. Adjusted for age, history of abortion and gravidity. 